\title{
Remembering Richard Paul
}

The Editors have just learned of the death of Richard Paul, founder of The Foundation for Critical Thinking and one of the leaders of the Critical Thinking movement. Dr. Paul, who suffered form Parkinson's Disease, died quietly in his sleep on August 30, 2015. The next issue of Informal Logic will carry a tribute to Richard Paul, who was an early friend to the journal and present at the conference that saw the birth of its predecessor, the Informal Logic Newsletter. 